\title{
Technology-Enhanced Learning: a Question of Knowledge
}

\section{JAN DERRY}

This paper is concerned with the human dimension of technology-enhanced learning; many suppositions are made about this but the amount of attention it has been given relative to that paid to technology is quite limited. It is argued that an aspect of the question that deserves more attention than it has received in the work on the application of technologies to education is epistemology on the grounds that the nature of knowledge and the general character of mind are critically important. As regards epistemology this paper draws on recent developments in philosophy by John McDowell and Robert Brandom that deal with the relation of mind to world and the nature of experience. From McDowell it draws on the idea of second nature and particularly the argument that human beings acquire their cognitive capacities by initiation into language and tradition. From Brandom it draws on the idea that humans stand apart from animals and machines in that they respond to reasons as well as to causes. It is argued that the implication of these ideas for education differ radically from the pedagogic models that underpin much work on technology-enhanced learning where the suppositions about experience are quite different. Indeed the nature of knowledge is usually presumed rather than examined and often what is taken for granted is awareness as a conceptually unmediated response to the world. These questions are raised in the context of so far disappointing results of the use of technologies to enhance learning.

Philosophy is set at a distance from concrete questions such as how technologies can be used to enhance learning. Nevertheless there is a significant if not immediate contribution that philosophy can make to technology-enhanced learning. It is widely recognised, for example, that presuppositions involving models of mind and theories of learning underpin attempts to integrate technologies into processes of learning. These presuppositions are also significant in questions concerning the enhancement of learning as they have implications for how technology is designed and applied. It is by making these presuppositions explicit that philosophy can work as an under-labourer, conceptualising attempts to utilise the power of technologies for learning. However, there is a further and more significant aspect to the work that philosophy can do as it happens that there is a coincidence of pedagogic and philosophic concerns centred on the unique characteristics of the human mind. We owe our distinctive cognitive powers to cumulative cultural evolution (Tomasello, 1999; Bakhurst, 2005), and thus philosophical investigations into the nature of mind and of knowing impinge directly on the question of the development of mind. This question is complicated since the environment in which the human mind develops has a history itself; and this history owes its form to the activities of human beings, which are in turn conditioned by the development of mind. In the light of this one can speak of human beings as both having and inhabiting a second nature. This, it is argued here, has implications for epistemology and through epistemology for learning. It is this connection between philosophy and education, and specifically the application of technologies to education, that is traced here. 
The use of digital technologies in education has so far not fulfilled expectations. Why is this so? Is it the intransigence of teachers? The constraints of schools? Or problems with the hardware and software? These factors are all too often blamed for the failure, and although possibly all bear some responsibility what will be considered here are other issues of an epistemological nature that require philosophical analysis. 'Technology-enhanced learning' (TEL) is a sweeping phrase encompassing an eclectic range of adaptations and usage, and therefore any philosophical points brought to bear run the risk of vagueness. In what follows I shall then set up a necessarily simplified characterisation but one that captures many of the assumptions informing practice, even though it may appear at first sight far removed from the issues involved.

In addition to the catch-all nature of the phrase 'technology-enhanced learning', the policy initiatives bringing technologies into education, particularly into mainstream schooling, are in a state of flux. The history of these initiatives shows a change in the focus of attention from an early emphasis on the technology itself towards a greater concern with the details of learning and the learner. In Europe this is illustrated by the recent adoption of the expression 'technology-enhanced learning' in place of 'information technologies' - or, in the case of the UK, 'information communication technologies'. Setting aside the natural emphasis on technologies as such, serious questions can be raised about the way and form in which the human element involved has been recognised. The importance of the primacy of the human element turns out to be much broader than at first appears, for what it involves is nothing less that a recognition of the distinctive quality of human contact with the world. One particularly significant aspect of the ongoing philosophical debate on this subject is the extent to which this human contact with the world is social.

This limited attention given to the role of teachers, in comparison to the volume of research placing emphasis on the technology itself, is understandable. In a period where technology is viewed as educationally indispensable, the authority of the teacher has been questioned, and learners are believed to 'create knowledge'. Against this background it is unsurprising that both policy and research agendas have grown around the issue of how technologies can advance learning, while problems of pedagogy and the acquisition of knowledge, which technologies are intended to resolve, have been neglected. Given the widespread and varied reference to 'pedagogy' in research on technology-enhanced learning, it may appear inappropriate to suggest the issue is neglected. But it is argued here that the pedagogical aspect central to any use of new technologies in education requires much closer examination than it is receiving, and that the unexamined pedagogic presuppositions informing use require spelling out.

So far the project to integrate technologies into education does not have a common research programme. The drive to integrate technologies into education carried all before it. In the rush to achieve results too much has been taken for granted about the way in which students learn. For instance, questions such as that of the social nature of mind have received little attention; and this is so because the pressure to speed up the utilisation of digital technologies has dictated the course of events, even though 
the human side of the equation is as crucial as the technical specification of technologies - arguably it is far more crucial.

The question of teacher autonomy is another matter requiring careful consideration in this context. Autonomy here means more than the freedom of teachers to exercise their judgment over curricula and pedagogic approaches since it extends to questions about the conditions necessary for the development of teachers as educators in the first place. In practice computers have been introduced into classrooms without taking such matters into account. In a recent Department for Education and Skills policy document, Harnessing Technology, government policy appears to give priority to the learners: "we aim to put learners, young people - and their parents - in the driving seat, shaping the opportunities open to all learners to fit around their needs and preferences' (Department for Education and Skills, 2005); but, although referred to, the issues concerning pedagogy and knowledge are at no point spelt out. Expressions like 'Technology can be mobile. That means e-learning can come to the learner' reveal unexamined suppositions that are still being made. They run as follows: There is such a thing as e-learning that exists in its own right. It can be brought to learners, just as water can be brought down irrigation channels to parched fields. Given the rhetoric that is bound to appear in a widely distributed policy document, it is no surprise that technology is presented as a panacea. The value of greater access to information is not a matter of dispute, but information and knowledge are not the same thing, and the availability of the one does not itself foster the growth of the other. Education involves far more than the acquisition of information and the ability to follow procedures. It also includes the development of capacities of judgment - that is, the capacity not merely to respond passively to events but to make decisions actively in different contexts; and it is here that the distinctive nature of our contact with the world - the distinction between human knowing and mechanical responsiveness - is significant.

\section{II}

Philosophy, in particular, has something to offer when questions about knowledge and knowing are central. The discussion of embodied, distributed and situated cognition, and the rise of the learning sciences that have been precipitated in part by the experience of introducing technologies into education, have posed questions about the nature of mind. What is argued in this paper is that the ideas about mind and world that have been developed by John McDowell and Robert Brandom are relevant to education even though they have not been applied by them in this area. There are three reasons for claiming their relevance: first, that their concern with the nature of knowledge has critical implications for pedagogy; second, that they offer a thorough critique of the conception of experience that by default informs much of the technological work in the area; and third, that they open questions often foreclosed about the distinctive nature of human thought.

It has been noted that 'computers have generally failed teachers and students' and that 'computers only benefit learning when they take into account what we know about how children learn, and when they are designed to be closely integrated with teacher and student interactions in the classroom' (Sawyer, 2006, p. xii). This goes some way towards accounting for the disappointing results of investing in computers in schools (Cuban, 2001). For instance, when some years ago Seymour Papert advocated the 
replacement of conventional classrooms with computers, it was not his intention to give the teacher a significant role (Papert, 1980). The contrast between

'instructionism' and 'constructionism' has been at the heart of the attempts to use technologies to lever traditional classrooms with poor practices into more active and inclusive learning environments. Difficulties arise from the fact that instructionism is contrasted unfavourably with the more 'active' practices integral to constructivist approaches. For instructionism is characterised in terms of its tendency 'to overvalue abstract reasoning', understood in terms of the isolation of 'pure essential factors from the details of concrete reality' and then attempting to pass these on (Papert, 1993). However, the target here is really the poor teaching practices that treat knowledge as though it were simply a collection of facts and procedures to be conveyed readymade. But, as these ideas have become generalised beyond specific examples, the idea of knowledge as authority has also been included in the target.

The growth of the Internet has come at a time when the status of knowledge and the integrity of knowledge domains are being called into question. In place of authoritative sources of knowledge, the internet, by providing large quantities of information in a non-authoritative fashion, appears to offer learners the possibility of constructing their own meanings based on their own interests and experiences. Much of the discourse on technologies in education emphasises interactivity, the possibilities for scaffolding learning and the constructive potential for learners to 'make their own meaning'. However, in the case of interactivity, for example, its human side is often not made explicit. What is downplayed is the nature of knowledge and the specific character of knowledge domains. In part the downplaying is a result of the general disenchantment with truth and knowledge as revelation. This idea of knowledge as something to be revealed is forcefully criticised by Richard Rorty (1981) in Philosophy and the Mirror of Nature, where he targets the correspondence view of truth, understood in terms of representations mapped on to objects. The wide disenchantment with such a conception of truth and the apparent disintegration of institutional structures that played a pivotal role in the development of knowledge coincided with the growth of a more popular belief that knowledge was a matter of personal construction. But this occurred without a proper regard to the domain within which this construction takes place. As a result, precise questions about knowledge have been pushed to the background, and attention has shifted to the contribution of computers - such as the possibilities they offer for interactivity, scaffolding and dialogue. Even though recent work has concentrated on more detailed questions of learning and pedagogy, the question of knowledge has been neglected. Consequently the weight being attached to the significance of the technology has not been adequately interrogated.

The focus on the learner, without adequate consideration of the nature of the knowledge domain, relies in part on the variety of epistemological assumptions underpinning the popularised idea of learners as constructors. In what Jerome Bruner called 'a policy document in our times' (Bruner, 1996, p. 33), Robert Reich captures the idea of learners as constructors of meaning when he speaks of the need for education to produce 'symbolic analysts', namely learners active in the conceptualisation of the knowledge. His claim in part rests on the idea that we are now part of the 'knowledge age' where 'data ... will be available . . at the touch of a computer key' (Reich, 1992, p. 229). Reich uses the contemporary discourse closely associated with new technologies to make a case for the importance of recognising 
that the specific powers of transformation and synthesis possessed by the 'symbolic analyst' are critical. The counterpart to this idea of the analyst ( here a version of constructivism in Reich's thought become apparent) is the concept of the world as devoid of meaning, bearing no particular truth apart from that arising from those constructive interventions imposed on it by humans. Reich writes: 'Consider first the capacity for abstraction. The real world is nothing but a vast jumble of noises, shapes, colours, smells and textures - essentially meaningless until the human mind imposes some order on them' (ibid.). When he writes this, he is giving expression to a dualist default position, common in contemporary thinking, including thinking about technologies in education.

It is precisely this dualism that McDowell takes to task. Once this view of the world is adopted responsibility for meaning is dependent entirely on human construction. The argument here is that this epistemological view goes along with neglect of the fact that at every point in time there is always a body or domain of knowledge about the world already in existence even if it is rejected by later generations as inadequate. Once the existence of these domains of knowledge, embodied in social practices and language, is recognised, questions concerning induction into them come to the fore. By implication, if they are not recognised, these questions have no grounds and thus appear pointless. At stake here is the account of experience that is presupposed.

Two world views can be counterposed at this point. One can be called Humean, a view that envisions a world of determining individuals acting on their desires and that prefigures the modern image of learners as consumers acquiring knowledge from the internet in much the same way as they might shoes from an online shoe store. (Katz et al., 1999, p. 54). The other might be termed 'Aristotelian'. It emphasises virtues of acquiring knowledge and dispositions by pursuing a discipline, where knowledge is acquired by discipline. On this view, the process of acquiring knowledge is as valuable as the knowledge by which it is acquired, as it instils in the learner a way of being in the world and acquiring what Aristotle means by virtue.

An alternative to the epistemological conception underlying the former position, which was originally inspired by Locke and then Hume, is McDowell's account of experience, which has roots in Aristotle, Hegel and Wittgenstein. This account starts by exorcising the anxieties of contemporary philosophy about how thought can be in touch with the world at all. Although it returns us to the position that we take for granted as it unfolds - that is to say, insisting that our thought is in contact with the world from the start, the route it takes to reach this position has fundamental importance for the educationalist, namely that we are not born human but become human in the course of maturity, not by virtue of some realisation of biologically given capacities but socially and culturally by induction into language and tradition (Bildung). This concept of human development, where the relation between cognition and the world is different from that envisaged in traditional empiricism, has consequences - in particular, that our contact with the world and thereby that growth in our knowledge can only take place as a moment in a more generalised process of development. This development is not simply due to maturation since this can take place only though initiation into an already humanised world, a process that actualises our second nature. The significance of McDowell's argument is that he resolves the quandary about how thought can get a grip on the world where there is an oscillation between two alternative positions - between a 'coherentism that renounces external constraints on thinking' and 'a vain appeal to the Given, in the sense of bare presences 
that are supposed to be the ultimate grounds of empirical judgements' (McDowell, 1996, p.24). But in unpacking what is presupposed in both positions - and this is where the force of his argument lies - McDowell shifts attention from what it is mistakenly assumed that we share with animals, to what it is that is distinctive about human beings. This is our responsiveness to reasons - which McDowell calls 'a good gloss on one notion of freedom'(p. xxiii). By shifting the focus to second nature in this way McDowell gives priority to the development of our cognitive capacities by initiation into language and tradition. In initiation far more is involved than simply the acquisition of the means for communication, since initiation into language is nothing less than initiation into the social practices that constitute meaning and establish the conditions within which reasons can be demanded and given. Through initiation into a language children are brought into 'a store of historically accumulated wisdom about what is a reason for what', and they thereby acquire 'the capacity to think and act' ( $p$. 126).

The account of Bildung as McDowell sees it may appear esoteric, but since it is relevant to the question of how children make generations of activity in the world their own it has obvious implications for education. McDowell has not explored these implications, and possibly this has left his own project incomplete and underdeveloped (Testa, I. 2007). Cognitive capacities (or what may be called the 'intellectual virtues') are developed through the induction of the child into culture, tradition and so on. These capacities are distinctively human, and it is their distinctiveness that is not taken into account in the epistemological positions that McDowell interrogates. In describing a 'kind of predicament that we tend to fall into when we think about aspects of the human condition', he reminds us that 'we tend to be forgetful of the very idea of second nature' (McDowell, 1996, p.85). It is claimed here that the work of bringing technology into education, is premised on this same epistemological forgetfulness, which makes proper recognition of the distinctive qualities of the human mind impossible. What makes McDowell's work important in this connection is that the epistemological assumptions involved in the positions he criticises inform much contemporary thinking about the application of technology to education.

\section{III}

At the heart of the dualist conception that informs so much of thinking about the use of technologies in education is a conception of experience relying upon what Wilfred Sellars called the Myth of the Given. The idea of the Given is the idea that we have immediate awareness of the world from the very start, without either language or reason, and that knowledge results from impressions that, having impinged on our senses, are interpreted by human construction. According to this view of things, concepts come into play late in the day after the world has already, so to speak, been taken in. Coupled to this idea of the Given is awareness understood in representational terms. This common sense way of thinking about meaning involves understanding signs or representations as having meaning solely by virtue of the objects they designate. In this commonsense approach accompanying constructivism in many writings on technology, although not obviously consistent with it, objects are believed to be the sole source of meaning, a meaning that is then conveyed to the receptor through their sign or representation. This approach is plausible in certain circumstance 
- for example, where animal predators see spiky features as unpalatable and respond automatically to them by backing off pursuit of the prey. But are human responses equally automatic in responding to the objects they come across? If so, then we might be correct in assuming that human beings learn in ways not very different from other forms of life. However, as soon as we consider the human infant, it becomes clear that it is responding in an environment where the significance that conditions its response, and thereby its contact with the world, is, in the first place, mediated by other human beings (i.e. it is being initiated into second nature). What is problematic in the picture of the animal and its environment is the idea that the stimulus to which the response is made inheres in the object or representation of the object (i.e. it is a Given). However in the case of the human infant, rather than the event or object being the sole source of the response, it is the parent or other significant actors who provide the active conditions that are decisive in giving meaning for the child's early responses. Vygotsky (1987) captured this process in his concept of a zone of proximal development. Meaning is attributed to the child's utterances and physical movements, and it is to this meaning that the parents respond, regardless of any intention on the part of the child to communicate meaning in the first place. In this sense, meaning is a product of a social process, and its significance relies on other actors and their relationships to each other and the world. This is what Vygotsky meant when he argued that what was first external and directed towards others is then exercised on oneself inwardly. This in turn accounts for the shift from external to internal development of the higher capacities of mind. For the use of a word, or the carrying out of an activity before fully understanding the meaning or significance of that activity, is a precursor through inner-directedness of understanding its significance. It might seem that the educational requirements of a social theory of mind must then be satisfied by a transition from classrooms where learners are only drilled in 'facts' to one where they manipulate, investigate, discuss and construct. But if this transition is effected simply by introducing technology into a classroom that itself remains unchanged (i.e. without consideration to human conditions and historically accumulated practices in knowledge domains), little if anything is likely to be achieved. In fact, it is possible that things will simply get worse.

Like McDowell, Robert Brandom (1994) also draws on Wilfred Sellars' critique of this concept of the Given, and he similarly takes issue with the idea of immediacy of awareness and its attendant conception of our relation to the world. Sellars' critique involves an attack not just on the idea of impressions as data, but on the entire 'framework of givenness' or what Hegel would call immediacy (Sellars, 1997) - that is, on the idea that our relation to the world is one of direct awareness. This may seem identical to common versions of the constructivist approach - that is, that what we see is dependent on our construction of it and not given to us by data. But what is really at stake here is not construction as such but the way this construction is effected: the question is at what point concepts enter the picture and how these concepts are acquired. Whereas the picture of mind and world that appears to inform Reich's view sees construction as arising from the ability of the analyst to construct meaning out of raw data, the alternative view, associated with Sellars, McDowell and Brandom, sees construction as originating through induction into what Sellars calls the space of reasons. It may be useful to point out that, in this context, the space of reasons contains both objects as well as subjects; it contains mind as well as world. The process that, on the one side, establishes humans in terms of second nature has its corollary, on the other, in the constitution of the world as data. 
Contrary to the idea of immediate awareness of the world as data impinging on our senses, Sellars' states in his attack on the myth of the given: 'In characterising an episode or a state as that of knowing, we are not giving a ... description of that episode or state; we are placing it in the ... space of reasons, of justifying and being able to justify what one says' (Sellars, 1996, p. 76). Responsiveness to the world does not start with our causal relation with raw data. It is immediately social in virtue of the development of our second nature, and this involves the actualisation of our cognitive capacities. So rather than our responses comprising merely causal relations with our environment, they take place, from the very start, within the space of reasons. This has consequences for how we think about the nature of experience since, according to McDowell, a normative context is necessary for being in touch with the world at all, whether knowledgeably or not.

In alerting us to the fact that knowing is not something that can arise by direct (unmediated) contact with the world, that it involves not just concepts but concepts in systematic relation to one another, Sellars introduces the Kantian conception of representation, a conception where judgments play an integral role. Our contact with the world as human beings with a second nature entails that our responses are governed by reasons as well as causes. In other words our responses are essentially normative in the sense that they depend upon the significance that human activities have given to objects, phenomena and events in the course of their activity in the world. Since Descartes and the development of modern science, epistemology has relied on a representational paradigm in which experience is understood in terms of perceiving minds making sense of a brute Given - what McDowell, 1996, calls a disenchanted world. This epistemological picture results in the problem of the nature of our contact with the world, a problem that has pre-occupied modern philosophy and that McDowell sets out to address. Without understanding that experience is already conceptual, we are left with an anxiety about how thoughts can be in touch with the world at all. The argument that experience is already conceptual goes against our common-sense intuition, yet these developments in philosophy provide rich resources for understanding the issues raised by the use of technologies to enhance learning.

The Cartesian epistemological picture criticised here forms a background to educational thought, including those relativistic forms of constructivism that argue that there is no way of ruling between one position and another and no convincing grounds for seeing progress in science or exercising any criteria of truth (Gergen, 1999). More importantly, it has led to a neglect of the question of knowledge and of the full extent of what is involved in bringing a learner into a knowledge domain. For philosophy it has led to an oscillation between a thorough-going coherentism - the position that only beliefs can justify beliefs, which takes away external constraints on our thinking - and the counter position where the external constraints on thinking are seen as absolute. Neither position provides a satisfying account of the relations of mind to world: each misses the active, productive character of our contact with the world; that is, each misinterprets experience as being outside of thought rather than containing thought itself, indeed as intricately entwined with the very possibility and constitution of thought. 
McDowell's exorcism of the Cartesian picture results in an account of experience as already conceptual. Humans inhabit not nature but second nature, and they are not subject to this in the way that animals are subject to nature. The world of second nature is already infused with meaning as a result of the practices and modifications of nature through which it has been brought about. McDowell's argument that human beings are 'born mere animals and they are transformed into thinkers and intentional agents in the course of coming to maturity' (McDowell, 1996, p. 125) has great significance for how we think about learning. Thought connects with reality only because to be a thinker is to inhabit the space of reasons, and powers of thought develop by being initiated into a language, into the "putatively rational linkages that constitute the space of reasons' (p. 186). This idea that experience is already conceptual is very different from any view that takes humans to be constructing meaning out of raw data.

And yet the idea that human beings do construct meaning out of raw data still forms the background to much educational thought. Hence, insufficient attention is given to the interrelation of knowledge and learning - or, to put it another way, to the importance of epistemology for education. The philosophical innovations touched on here draw a different line between mind and world, or in McDowell's terms between reason and nature, than that drawn in the Cartesian picture. In this alternative to what McDowell calls 'bald naturalism', nature includes second nature since human thoughts are as much a part of nature as the activities of animals. In this respect the modification of nature, which this capacity to think has made possible, also counts as natural. Drawing the line between mind and world differently, this view places far greater weight not just on knowledge and its constitution but on the activity of coming to know.

If we accept the idea that when we respond to an environment, we do so within a space of reasons, we can appreciate what distinguishes human knowing from animal or mechanical responsiveness. Brandom (2000) illustrates this idea with a simple example when he asks us to consider what distinguishes human responsiveness from that of a machine or animal. He takes an example of the contrast between a fire alarm and a human being shouting the warning 'Fire!' Fire alarms may well respond more effectively and reliably to the stimuli of fire than the human being. Their sensors are probably more sensitive than human organs, the sounds they make more compelling of attention. But Brandom asks us to contrast a child shouting 'Fire' with the mechanical alarm and consider what initiates the response. With the alarm the response is the end point of a causal chain in which smoke hits sensors and activates a process resulting in a siren sound. However, for the child reasons are involved from the very start, even if initially only as background to her response, before she becomes fully aware of them. Unlike an alarm, which responds mechanically to temperature and smoke, etc., the child has a concept of fire and therefore an appreciation of its consequences, though this appreciation may be limited and developing. In other words the response of the child is not a reflex. Even though it may be automatic and in this sense not entail conscious thought, it nonetheless involves responsiveness to reasons; that is, it involves thought. This the machine lacks. For the child the fire is the reason for the alarm and not merely the cause, because the child perceives the fire as fire; unlike a machine, the child has a concept of fire as part of a system of concepts. For Brandom, making a report as a human being is not 'responding differentially' since it involves inferring rather than merely representing. Brandom's argument rests on a 
critique of the dominant representational paradigm and on the claim that, insofar as human contact with the world is concerned, we need to privilege inference over representation; our awareness should not be understood primarily in representational terms but in terms of the inferential space that we inhabit as thinking creatures. Awareness of any one concept is dependent on awareness of a range of other concepts that constitute its meaning in the first place.

This distinction that Brandom draws between reacting differentially and responding to reasons, a distinction already drawn in German idealist thought at the end of the eighteenth century, has a contribution to make to the problems that arise with the application of technology to education. For, once the idea of immediacy is rejected and it is recognised that the awareness of human beings operates within a space of reasons, it is clearly the task for educators not only to provide learners with rich data from which they can construct meanings but also to move them from the space of reason within which they start to that of the knowledge domain they are studying. The knowledge to which learners qua learners are introduced is different from the knowledge that arises from everyday experience. Education as the means by which hard-won knowledge is passed from one generation to the next involves practices and objects that are not the content of everyday lives, however important they may be for it. The knowledge with which education is concerned cannot be acquired without conscious and purposeful involvement by both teachers and learners regardless of the setting (Young, 2008).

As far as pedagogy is concerned, the priority of inference over reference means that the grasping of a concept involves the learner's committing to the inferences implicit in its use in social practices of giving and asking for reasons. Effective teaching involves providing the opportunity for learners to operate with a concept in the space of reasons within which it falls and through which its meaning is constituted. Participation in such a space does not require an immediate and full grasp of the concept from the start, but rather only the ability to inhabit the space in which reasons constituting the concept operate.

\section{IV}

Technology offers the possibility of engaging with the world before fully knowing it (Noss and Hoyles, 1996); it enables us to gain access to inferential relations between concepts before fully acquiring the concepts involved. Digital technologies make it possible to bring changes in the relationships between concepts and hence their meanings into plain view. However, this requires not only a high level of pedagogic design but also active participation by both teacher and learners. It is not the concepts themselves and their referents that are the object of learning, but their meaning as governed by their systemic relation to one another. Through being inducted into the inferential relations between concepts, learners begin to understand what it is to $d o$ mathematics and history and so on. Giving inference priority over representation means that pedagogic design must focus not on individual concepts but on the knowledge domains that constitute them. This is a more exacting task for design than dealing with concepts alone. This pedagogic strategy that recognises inferential systems requires much more time and effort than the more common approach that treats concepts as representations. 
An example of the way in which a technology facilitates the use of concepts before they are fully grasped is the programming language Logo. This, as is widely known, allows children to explore mathematical relations concretely before they have any idea of what explains them in abstract terms. But while a technology like Logo can make visible the inferential relations that constitute concepts, as for instance when the making of a triangle reveals the specifications of the figure, the advantages of this will only be properly realised when the technology is used as an element in a programme in which priority is given to knowledge domains. To make it work effectively not only do teachers need to be there when they guide the learner, but they need to have a clear understanding of the priority of the particular knowledge domain in mind. However, the lack of recognition of what is involved in teaching, in terms of the development of cognitive capacities, has meant that the time and resources required by such a way of teaching are well beyond what is available for teachers preparing for lessons in most contemporary classrooms.

The application of technology without adequate attention to the knowledge domain runs into problems that can be traced back to the way that learning is based on the weak and narrow conception of experience criticised here. Certainly it is true that, as far as the application of technology to education is concerned, it is generally recognised that the exposure of learners to rich information is insufficient by itself. But there is far from full agreement about what steps are needed to augment it. In this connection the argument made by Nicolas Balacheff, who acted as scientific manager for the Kaleidoscope European research network on technology enhanced learning, is particularly relevant.

A concentration on learning with little or no attention paid to the question of knowledge as such is criticised by Balacheff, who argues for 'design supported by a deep epistemological analysis of the domain considered' (Balacheff, 2004). Noting that the project to bring technologies into education started with the push of technology and only later, at the close of the twentieth century, turned to the learnerdriven principle of design, Balacheff argues that the project will not be soundly based until knowledge is placed at the centre of learning: 'The agreement we might reach on a 'learning driven' principle of design of technology enhanced learning (TEL) environments would in the end prove as disappointing as the naïve and initial focus on technology per se and the subsequent reaction by the focus on the learner' (ibid.). He goes on to argue that the term learning has no meaning unless it is concerned with knowledge. In other words focus on the learners without recognition of knowledge domains offers no way forward: "After sixty years of research . . . in the field of TEL we are sent back to the understanding of knowledge[, and] that understanding knowledge is a strategic condition for the development of TEL from a theoretical as well as from an operational perspective' (ibid.).

There is then what appears to be a mundane but is in fact the central, on-going problem in the classroom: how those learners who are least engaged in contemporary classrooms can become engaged by the use of technology. Even where learners are motivated, their orientation towards what it is that they are to make sense of cannot necessarily be assumed to be adequate (Arnseth and Säljö, 2007). To underline this argument, it must be stated that adequacy is not the serial learning of concepts on a scale of growing complexity, what is required is entry into a knowledge domain, with 
all that is implied by this. Moreover the approach must vary from domain to domain, for as Balacheff points out:

The characteristics of the milieu for the learning of mathematics, of surgery or of foreign languages are fundamentally different. . [O]ne may say that the milieu for surgery is part of the 'material world' (here, the human body), for foreign languages it includes human beings, for mathematics already a theoretical system. Although these observations seem obvious most of the ICT projects claim they contribute to TEL research at a general level and they pretend to be domain independent (ibid.).

Recognising the provocative nature of what he is saying, he continues 'A devil's advocate may say that ICT research does not see itself being accountable beyond the coherency and robustness of the software it produces, not to mention the constraint of re-usability often mentioned to justify the search or claim for domain independence' (ibid.). In fact, it is possible that the proper design of technology-enhanced learning environments is an even more complicated matter than Balacheff believes since not only do knowledge domains vary as regards content but so also do conceptual frameworks and what counts as a reason for what. In fact matters are even more complicated when one moves from the sciences and mathematics to the humanities and the arts.

If Balacheff's claim about knowledge were taken seriously, many of the projects to implement technology-enhanced learning would have to be radically restructured. For the conclusion to which his work points would demand a turning of attention away from the technology to the knowledge domain, from here to questions of pedagogy and from there one step further, back to epistemology.

Correspondence: Jan Derry, Philosophy Section and London Knowledge Lab, Institute of Education, University of London, 20 Bedford Way, London WC1H 0AL, UK.E-mail: j.derry@ioe.ac.uk.

\section{REFERENCES}

Bakhurst, D. (2005) Ilyenkov on Education, Studies in East European Thought, Springer, Netherlands.

Balacheff, N. (2004) Knowledge the keystone of TEL design Proceedings of the 4th Hellenic conference Information and communication technologies in education, Athens, Greece (2004) also available on TeLearn at http://telearn.noekaleidoscope.org/

Brandom, R. (1994). Making it Explicit: Reasoning, Representing, and Discursive Commitment. (Cambridge, MA: Harvard University Press)

Brandom, R. (2000). Articulating Reasons: an introduction to inferentialism. (Cambridge, MA: Harvard University Press) 
Bruner, J. S. (1996) The Culture of Education Cambridge, MA: Harvard University Press.

Cuban, L. (2001) Oversold and Underused: Computers in the Classroom. (Cambridge, MA: Harvard University Press)

Department for Education and Skills (2005) Harnessing Technology: Transforming Learning and Children's Services, Reference: DFES-1437-2005

Gergen, K.J. (1999). An Invitation to Social Construction. (London: Sage Publications)

Katz, R.N. and associates (1999) Dancing with the Devil: Information Technology and the New Competition in Higher Education (Jossey-Bass Higher and Adult Education Series)

Noss, R. \& Hoyles, C. (1996) Windows on Mathematical Meanings: Learning Cultures and Computers. Dordrecht: Kluwer.

McDowell, J. (1996). Mind and World (Cambridge, MA: Harvard University Press)

Papert, S. (1980) Mindstorms: Children, Computers and Powerful Ideas Basic Books.

Papert, S. (1993) The Children's Machine: Rethinking School in the Age of the Computer. Basic Books.

Reich, R. (1992) The Work of Nations: Preparing Ourselves for $21^{\text {st }}$ Century

Capitalism New York: Vintage Books, A Division of Random House, Inc.

Rorty (1981) Philosophy and the Mirror of Nature, Princeton University Press.

Arnseth, H.C., Säljö, R. (2007) Making sense of epistemic categories. Analysing students' use of categories of progressive inquiry in computer mediated collaborative activities, Journal of Computer Assisted Learning. 23, 5, pp. 425-439

Sellars, W. (1997) Empiricism and the Philosophy of Mind, with an introduction by Richard Rorty and a study guide by Robert Brandom, Harvard University Press.

Testa, I. (2007) Criticisms from within nature: The dialectic between first and second nature from McDowell to Adorno, Philosophy and Social Criticism, 33, 4, pp 473497

Tomasello, M. (2001) The Cultural Origins of Human Cognition, Harvard University Press.

Vygotsky, L.S. (1987). The Collected Works of L.S. Vygotsky, Volume 1 Problems of General Psychology, (including the Volume Thinking and Speech). Minick, N. (trans.), Reiber, R.W. \& Carton, A.S. (Eds). (New York: Plenum Press) 
Young, M. F. D. (2008) Bringing Knowledge Back In: From social constructivism to social realism in the sociology of education, Routledge. 